Metal-Catalyzed

Asymmetric

Synthesis and

Stereoselective

Reactions

\title{
Epoxidation of Terminal Alkenes with Chiral Pt Complexes
}

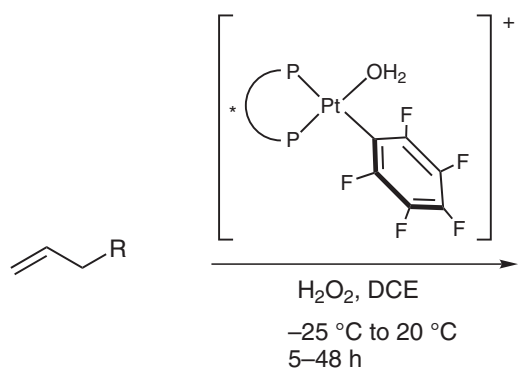

Selected examples

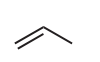

$98 \%$ yield $58 \%$ ee
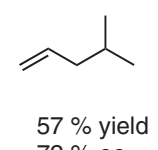
$72 \%$ ee

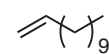

$81 \%$ yield $71 \%$ ee

Epoxidation of dienes

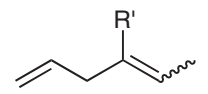

$\mathrm{R}^{\prime}=\mathrm{H}, \mathrm{Me}$

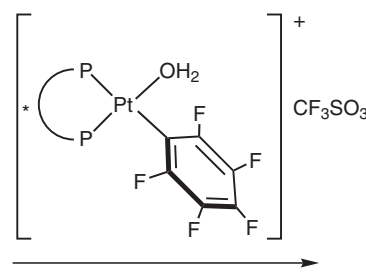

$\mathrm{H}_{2} \mathrm{O}_{2}$, DCE
$\mathrm{CF}_{3} \mathrm{SO}_{3}{ }^{-}$
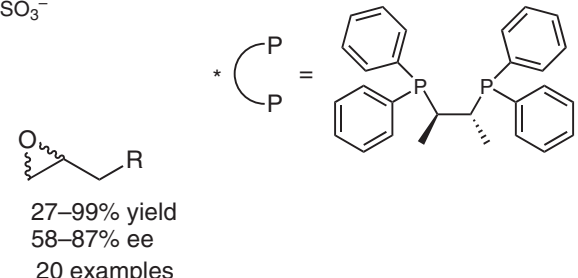

20 examples

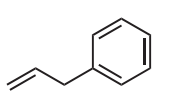

$79 \%$ yield

$75 \%$ ee
Key words

platinum

epoxidation

olefins

P-ligands

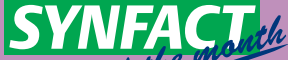

Significance: Asymmetric epoxidation of alkenes is a very well known reaction that has been studied utilizing a range of chiral catalysts. However, unfunctionalized terminal olefins remain challenging because of their inherent low reactivity and the difficulty to distinguish the two prochiral faces. This new catalyst was found to be highly reactive and selective for unfunctionalized terminal alkenes.
Comment: The use of hydrogen peroxide and a highly reactive Pt complex makes this an attractive system for use in asymmetric epoxidation. Furthermore, the high selectivity for less reactive terminal alkenes makes this method more impressive. The high yields, chemoselectivity, and enantioselectivity with a broad substrate scope show that this simple system could be applied to many situations in organic chemistry. 